\title{
Thermodynamic modeling of ionic liquid density with heterosegmented statistical associating fluid theory
}

\author{
Xiaoyan Ji ${ }^{\mathrm{a}, *}$, Hertanto Adidharma ${ }^{\mathrm{b}}$ \\ ${ }^{a}$ Division of Energy Engineering, Luleå University of Technology, 97187 Luleå, Sweden \\ ${ }^{\mathrm{b}}$ Soft Materials Laboratory, Department of Chemical and Petroleum Engineering, University of Wyoming, Laramie, WY 82071-3295, USA
}

\section{A R T I C L E I N F O}

\section{Article history:}

Received 21 October 2008

Received in revised form 7 January 2009

Accepted 14 January 2009

Available online 22 January 2009

\section{Keywords:}

State equation

Statistical thermodynamics

Statistical associating fluid theory

Ionic liquid

\begin{abstract}
A B S T R A C T
Heterosegmented statistical associating fluid theory is used to represent the density of ionic liquid. Ionic liquid molecule is divided into several groups representing the alkyls, cation head, and anion. The cation of ionic liquid is modeled as a chain molecule that consists of one spherical segment representing the cation head and groups of segments of different types representing different substituents (alkyls). The anion of ionic liquid is modeled as a spherical segment of different type. To account for the electrostatic/polar interaction between the cation and anion, the spherical segments representing cation head and anion each have one association site, which can only cross associate to each other. The parameters for alkyls are obtained from those of the corresponding $n$-alkanes and the parameters of groups representing cation head and anion, including the two association parameters, are fitted to a group of experimental ionic liquid data. The performance of the model is examined by describing the densities of three important series of imidazolium-based ionic liquids, i.e., $\left[C_{n} \operatorname{mim}\right]\left[\mathrm{Tf}_{2} \mathrm{~N}\right],\left[\mathrm{C}_{\mathrm{n}} \mathrm{mim}\right]\left[\mathrm{BF}_{4}\right]$, and $\left[\mathrm{C}_{\mathrm{n}} \mathrm{mim}\right]\left[\mathrm{PF}_{6}\right]$. The model is found to well represent the densities of these ionic liquids from 293.15 to $415 \mathrm{~K}$ and up to $650 \mathrm{bar}$, and well capture the effects of temperature, pressure, and alkyl types on density.
\end{abstract}

(c) 2009 Elsevier Ltd. All rights reserved.

\section{Introduction}

Ionic liquids (ILs) have been the subject of increasing attention due to their unique physicochemical properties such as high thermal stability, large liquid range, high ionic conductivity, high solvating capacity, negligible vapor pressure, and non-flammability that make them ideal solvents for green chemistry. ILs also offer significant cost reduction and environmental benefits because they can be used without losses, in contrast to the volatile organic compounds used nowadays. ILs are often referred to as designer solvents because the cation head, anion, and alkyl chains of an IL can be selected from among a huge diversity to obtain an appropriate IL for a specific purpose.

The designs of industrial processes and new products involving ILs are only possible when the thermophysical properties of ILs are adequately known. A growing number of experimental investigations on IL properties have been reported (Gardas et al., 2007a,b; Tomida et al., 2006, 2007a,b; de Azevedo et al., 2005a,b; Tekin et al., 2007; Esperanca et al., 2006, 2008; Jacquemin et al., 2007), but

\footnotetext{
* Corresponding author. Tel.: +46920 492837; fax: +46920491074

E-mail address: xiaoyan.ji@ltu.se (X. Ji).
}

due to the vast number of ILs that can be tailored the number of experimental investigations needed is less than adequate. Since experimental measurements are usually time-consuming and expensive, it is desirable to have predictive models for calculating the IL properties.

Several thermodynamic models have been proposed to represent the properties of ILs. Excess Gibbs energy models and cubic equations of state, in which an IL molecule was modeled as a single molecular species or assumed to completely dissociate into cation and anion (Simoni et al., 2008; Gardas et al., 2008; Shiflett and Yokozeki, 2007; Shin et al., 2008), have been investigated. Statistical associating fluid theory (SAFT)-based models were proposed recently, where an IL molecule was modeled as a neutral ion pair with one set of parameters (Karakatsani et al., 2007; Kroon et al., 2006; Andreu and Vega, 2007). In the models of heteronuclear square-well chain fluids (Wang et al., 2007), group-contribution non-random lattice fluid equation of state (Kim et al., 2007), and group contribution equation of state (Breure et al., 2007), the imidazolium ring-anion pair was modeled as one segment or functional group. As can be concluded from those works, all of these models utilize model parameters that are not completely transferable. Since the types of alkyl substituents, cation head, and anion of ILs are known to affect the properties of ILs, it is still highly desirable to have a model that can predict the properties of ILs based on the information of their alkyl substituents, 
cation head, and anion. This could be done by using, for example, a heterosegmented SAFT equation of state.

In our previous work, a heterosegmented SAFT, referred to as SAFT1, has been developed to describe the properties of copolymer solutions, which were modeled as molecules having two different segments (Adidharma and Radosz, 1998). By using the same model, the properties of $n$-alkanes were also well represented (Adidharma and Radosz, 1998). We have also developed another version of SAFT, i.e., SAFT2 (Tan et al., 2006; Ji et al., 2006; Ji and Adidharma, 2006, 2007, 2008), which will be extended in this work to describing the properties of ILs. In this first attempt, the densities of three important series of imidazolium-based ILs, i.e., $\left[C_{n} \operatorname{mim}\right]\left[\mathrm{Tf}_{2} \mathrm{~N}\right],\left[\mathrm{C}_{n} \mathrm{mim}\right]\left[\mathrm{BF}_{4}\right]$, and $\left[C_{n} m_{i m}\right]\left[\mathrm{PF}_{6}\right]$, in wide temperature and pressure ranges are modeled.

\section{Thermodynamic modeling}

Generally, IL consists of a large organic cation and a weakly coordinating inorganic or organic anion. The large organic cation consists of a cation head and several alkyls. It has been stated that IL dissociates into cation and anion (Simoni et al., 2008), but due to the strong interaction between the cation and the anion the IL molecules take the form of ionic pairs. For example, for $[\mathrm{bmim}]\left[\mathrm{PF}_{6}\right]$, it was concluded from quantum-mechanical and molecular dynamics studies that the strong interaction between the cation and the anion, leading to the formation of ionic pairs, was due to hydrogen bonding between the fluorine atom in the anion and the hydrogen atom at C2 in the aromatic ring of the cation (cation head) (Meng et al., 2002; Antony et al., 2004).

Therefore, in this work, the IL is modeled as a chain molecule representing the cation with a spherical segment representing the anion. The chain molecule consists of one spherical segment representing the cation head of the IL and groups of segments of different types representing different substituents (alkyls). The segments are not necessarily identical with functional groups. The effective number of segments representing the alkyls thus may or may not be an integer. For example, IL [bmim] $\left[\mathrm{PF}_{6}\right]$, as shown in Fig. 1, consists of [bmim] $]^{+}$ (cation) and $\left[\mathrm{PF}_{6}\right]^{-}$(anion). The cation consists of three groups with different types of segments representing butyl (A), methyl (B), and imidazolium cation head (C). The anion is assumed to be a single segment representing $\left[\mathrm{PF}_{6}\right]^{-}$as a whole (D). The spherical segments representing cation head (C) and anion (D) each have one association site, which can only cross associate to each other; the occurrence of ionic pairs due to the occurrence of the hydrogen bonding in addition to the Coulombic interactions between the cation and the anion allows us to lump the electrostatic/polar interactions between the cation and anion together as association interaction.

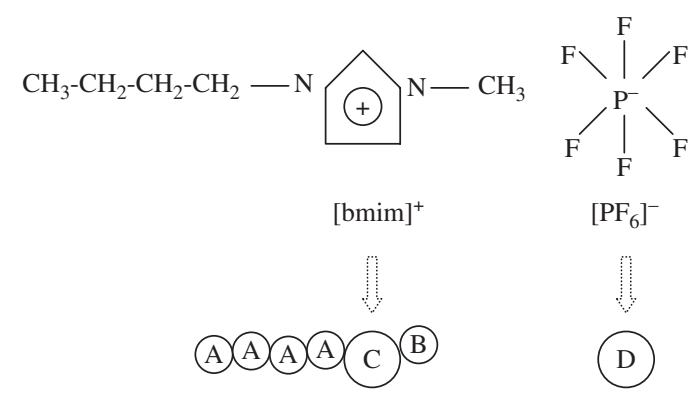

Fig. 1. Schematic of molecular models for $[\mathrm{bmim}]\left[\mathrm{PF}_{6}\right]$.

\subsection{Heterosegmented SAFT}

The heterosegmented SAFT is defined in terms of the dimensionless residual Helmholtz free energy as follows:

$\tilde{a}^{\text {res }}=\tilde{a}^{h s}+\tilde{a}^{\text {disp }}+\tilde{a}^{\text {chain }}+\tilde{a}^{a s s o c}$

where the superscripts on the right side refer to terms accounting for the hard-sphere, dispersion, chain, and association interactions, respectively.

IL molecule is divided into several groups representing the alkyls, cation head, and anion. Similar to the backbone-branch groups approximation (Tan, 2004) (a simplified group contribution approach), for this heterosegmented SAFT, each group has five parameters, i.e., segment number $m$, segment volume $v^{o o}$, segment energy $u / k$, the reduced range of the potential well $\lambda$, and group bond number $n_{B}$, which is the effective number of bonds contributed by the group and used to calculate the bond fraction in the chain term. Unlike cation, the anion of IL is represented by a single spherical segment, not a chain molecule, and thus its group bond number is zero (no chain term for the anion). The mixing rules for parameters $v^{o o}, u$, and $\lambda$ are the same as those in our previous work (Ji and Adidharma, 2007). In addition to these parameters, the groups representing cation head and anion also have two association parameters, i.e., the well depth of the association site-site potential $\varepsilon$ and the parameter related to the volume available for bonding $\kappa$. The association interaction can only occur between two different association sites (cross association).

The hard-sphere, dispersion, and chain terms have been described in our previous work (Ji and Adidharma, 2007). The association term for homosegmented molecule is extended to heterosegmented molecule as follows:

$\tilde{a}^{a s s o c}=\sum_{i} X_{i} \sum_{\alpha}\left[\sum_{A_{\alpha i}}\left(\ln X^{A_{\alpha i}}-\frac{X^{A_{\alpha i}}}{2}\right)+\frac{n\left(\Gamma_{\alpha i}\right)}{2}\right]$

where $X_{i}$ is the mol fraction of component $i, n\left(\Gamma_{\alpha i}\right)$ is the number of association sites on segment $\alpha$ in molecule $i$, and $X^{A_{\alpha i}}$ is the mole fraction of molecule $i$ not bonded at side $A$ of segment $\alpha$ calculated from

$X^{A_{\alpha i}}=\frac{1}{1+\rho_{n} \sum_{j} X_{j} \sum_{\beta} \sum_{B_{\beta j}} X^{B_{\beta j}} \Delta^{A_{\alpha i} B_{\beta j}}}$

In Eq. (3), $\rho_{n}$ is the number density and

$\Delta^{A_{\alpha i} B_{\beta j}}=F^{A_{\alpha i} B_{\beta j}} \mathrm{e}^{\alpha(\rho) u_{\alpha \beta} / k T} g_{\alpha \beta}^{h s}\left(\sigma_{\alpha \beta}\right)\left(\sigma_{\alpha \beta}^{3} \kappa^{A_{\alpha i} B_{\beta j}}\right)$

$F^{A_{\alpha i} B_{\beta j}}=\exp \left(\frac{\varepsilon^{A_{\alpha i} B_{\beta j}}}{k T}\right)-1$

where $\alpha(\rho)$ and the pair distribution function of hard-sphere segments $g^{\text {hs }}$ have been described in our previous work (Ji and Adidharma, 2007), and

$\left\{\begin{array}{l}\sigma_{\alpha \beta}=\frac{\sigma_{\alpha}+\sigma_{\beta}}{2} \\ \sigma_{\alpha}=\left(\frac{\sqrt{2}}{N_{A v}} v^{o o}\right)^{1 / 3} \\ \varepsilon^{A_{\alpha i} B_{\beta j}}=\sqrt{\varepsilon^{A_{\alpha i} \varepsilon^{B_{\beta j}}}} \\ \kappa^{A_{\alpha i} B_{\beta j}}=\frac{1}{\sigma_{\alpha \beta}^{3}}\left[\frac{\left(\sigma_{\alpha}^{3} \cdot \kappa^{\left.A_{\alpha i}\right)^{1 / 3}}+\left(\sigma_{\beta}^{3} \cdot \kappa^{B_{\beta j}}\right)^{1 / 3}\right.}{2}\right]^{3}\end{array}\right.$

In Eq. (6), $\sigma_{\alpha}$ is the diameter of segment $\alpha, N_{A v}$ is the Avogadro number, and the superscript $A_{\alpha i} B_{\beta j}$ denotes the cross association 
parameter between site $A$ on segment $\alpha$ in component $i$ and site $B$ on segment $\beta$ in component $j$.

To capture the effect of temperature on the properties of ILs, we allow the segment energies for the groups representing cation head and anion to be temperature-dependent with the following expressions:

$\frac{u}{k}= \begin{cases}c_{1}+c_{2} \cdot T+c_{3} \cdot T^{2} & \text { cation head } \\ c_{1}+c_{2} \cdot T & \text { anion }\end{cases}$

where $T$ is the temperature in Kelvin, and $c_{1}, c_{2}$, and $c_{3}$ are coefficients.

\subsection{Parameter estimation}

To represent the properties of ILs with the heterosegmented SAFT, the parameters of groups representing alkyls, cation head, and anion are required. In the works that have been done (Wang et al., 2007; Adidharma and Radosz, 1998), the parameters of alkyls were approximated by those of the corresponding $n$-alkanes, which implies that the properties of alkyls were assumed to be the same as those of the corresponding $n$-alkanes. This is of course untrue, especially for shorter alkyls. In this paper, a method used in backbone-branch groups approximation (Tan, 2004) is implemented to estimate the parameters for alkyls. The parameters for groups representing cation head and anion, including the two association parameters, are fitted to a group of experimental IL data.

\subsubsection{Parameters for alkyls}

In the backbone-branch groups approximation (Tan, 2004), a $n$-alkane molecule is assumed to consist of two alkyl groups, i.e., one methyl group and the balance group, for example: ethane consists of two methyl groups; propane consists of one methyl and one ethyl group, $n$-pentane consists of one methyl and one butyl group; etc. The sum of $m$ of these two alkyl groups gives the effective number of segments of the $n$-alkane and the sum of $n_{B}$ of these two alkyl groups gives the effective number of bonds $(m-1)$ of the $n$-alkane. The $m$-weighted average of parameters $v^{o o}, u / k$, and $\lambda$ of these two alkyl groups gives the parameters of the $n$-alkane. Thus, the parameters for these alkyl groups can be estimated directly from those for $n$-alkanes, which are taken from our previous work (Tan et al., 2006).

Specifically, the parameters of methyl are obtained from those of ethane. Since the ethane molecule consists of two methyl groups, the parameters $v^{o o}, u / k$, and $\lambda$ of a methyl group are identical to those of ethane, while its number of segments $m$ is equal to $\frac{2}{3}$ (the number of segments of ethane is $\frac{4}{3}$ ) and its bond number $n_{B}$ is $\frac{1}{6}$ (the number of bonds of ethane is $\frac{1}{3}$ ). The parameters of other alkyls are then derived from those of methyl group and the corresponding $n$-alkanes. For $m$ and $n_{B}$ of alkyls, we have

$m=\frac{n+1}{3}$

$n_{B}=\frac{2 n-1}{6}$

where $n$ is the number of carbons. The other parameters of alkyls obtained in this work are listed in Table 1.

We plot the parameters of $v^{o o}, u / k$, and $\lambda$ against the molecule weight (MW), as shown in Fig. 2. As expected, the parameters are well behaved and can be represented by the following equations:

$m v^{o o}=0.600713 \mathrm{MW}+2.22445$

$m \frac{u}{k}=6.72171 \mathrm{MW}+29.6527$

$m \lambda=0.0377047 \mathrm{MW}+0.48767$
Table 1

Parameters $v^{o o}, u / k$, and $\lambda$ for alkyls

\begin{tabular}{lclll}
\hline$n$ & MW $(\mathrm{g} / \mathrm{mol})$ & $v^{o 0}\left(\mathrm{~cm}^{3} / \mathrm{mol}\right)$ & $u / k(\mathrm{~K})$ & $\lambda$ \\
\hline 1 & 15.035 & 16.9740 & 194.6721 & 1.5628 \\
2 & 29.062 & 19.7362 & 227.0978 & 1.5666 \\
3 & 43.088 & 21.1998 & 238.8779 & 1.5846 \\
4 & 57.115 & 21.8387 & 247.2764 & 1.5897 \\
5 & 71.142 & 22.4333 & 253.2574 & 1.5897 \\
6 & 85.169 & 22.8280 & 256.9062 & 1.5910 \\
7 & 99.196 & 23.1253 & 259.1726 & 1.5926 \\
8 & 113.222 & 23.4905 & 262.1160 & 1.5908 \\
9 & 127.249 & 23.4833 & 267.4389 & 1.5832 \\
11 & 155.303 & 23.9364 & 271.5238 & 1.5802 \\
13 & 183.356 & 24.1598 & 271.7395 & 1.5829 \\
15 & 211.410 & 24.1988 & 271.0103 & 1.5872 \\
19 & 267.517 & 24.4288 & 273.4217 & 1.5865 \\
\hline
\end{tabular}
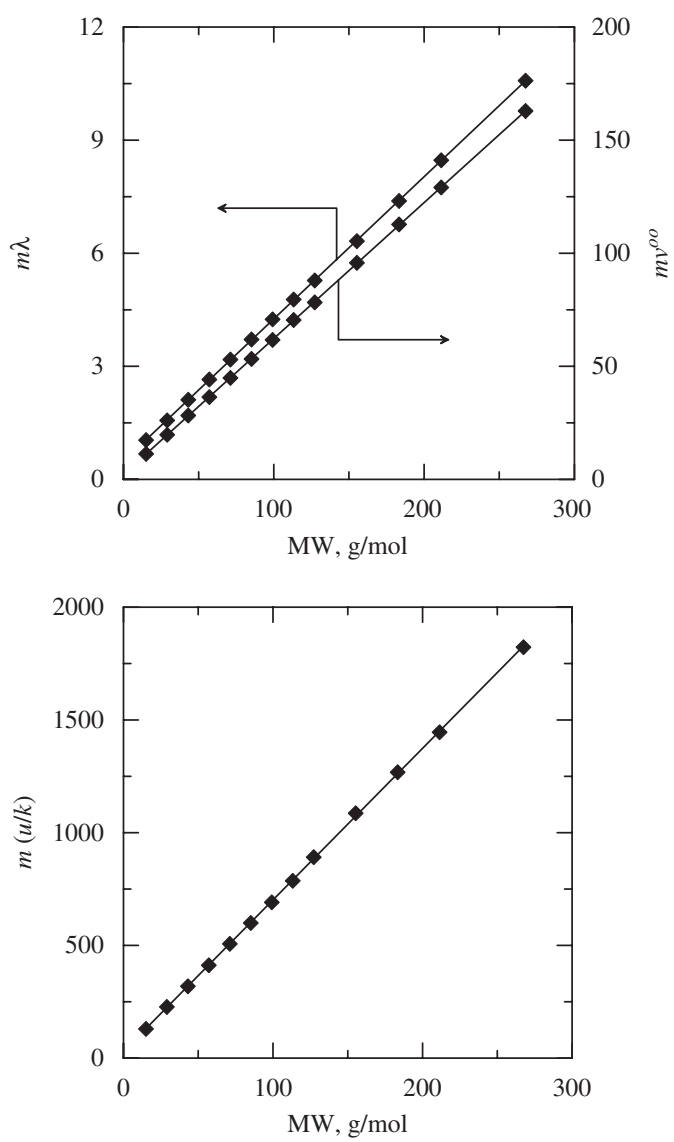

Fig. 2. The parameters for alkyls as functions of molecular weight. $\downarrow$, values listed in Table $1 ;-$, Eq. (9).

These equations provide a basis for estimating parameters for longer alkyls.

\subsubsection{Parameters for groups representing cation head and anion}

The parameters for groups representing cation head and anion, including the two association parameters, are fitted to a group of experimental IL data. At the temperature and pressure of interest, most of ILs have very low or negligible saturation vapor pressures and, to the best of our knowledge, no reliable experimental measurements of saturation vapor pressure are available. Therefore, only experimental liquid densities of ILs are used in parameter fitting.

The $\left[C_{n} \operatorname{mim}\right]\left[\mathrm{Tf}_{2} \mathrm{~N}\right],\left[\mathrm{C}_{\mathrm{n}} \mathrm{mim}\right]\left[\mathrm{BF}_{4}\right]$, and $\left[\mathrm{C}_{\mathrm{n}} \mathrm{mim}\right]\left[\mathrm{PF}_{6}\right]$ ILs are of our interest, in this work, because their experimental liquid densities 
Table 2

Experimental data used for parameter fitting.

\begin{tabular}{|c|c|c|c|c|c|}
\hline Ionic liquid & $T, \mathrm{~K}$ & $P_{\max }$, bar & $A R D_{1}(\%)$ & $A R D_{2}(\%)$ & Ref. \\
\hline$\left[\mathrm{C}_{2} \operatorname{mim}\right]\left[\mathrm{Tf}_{2} \mathrm{~N}\right]$ & 293.15-393.15 & 300 & 0.12 & 0.17 & Gardas et al. (2007a) \\
\hline$\left[\mathrm{C}_{7} \operatorname{mim}\right]\left[\mathrm{Tf}_{2} \mathrm{~N}\right]$ & 293.15-393.15 & 300 & 0.12 & 0.11 & Gardas et al. (2007a) \\
\hline$\left[\mathrm{C}_{8} \operatorname{mim}\right]\left[\mathrm{Tf}_{2} \mathrm{~N}\right]$ & 293.15-393.15 & 300 & 0.13 & 0.11 & Gardas et al. (2007a) \\
\hline$\left[\mathrm{C}_{2} \mathrm{mim}\right]\left[\mathrm{BF}_{4}\right]$ & 293.15-393.15 & 300 & 0.22 & 0.21 & Gardas et al. (2007a) \\
\hline \multirow[t]{3}{*}[\mathrm{C}_{4}\mathrm{mim}]{$\left[\mathrm{BF}_{4}\right]$} & 293.15-393.15 & 100 & 0.68 & 0.71 & Gardas et al. (2007b) \\
\hline & 293.15-353.15 & 200 & 0.24 & - & Tomida et al. (2006) \\
\hline & $298.15-398.15$ & 400 & 0.24 & - & Tekin et al. (2007) \\
\hline$\left[\mathrm{C}_{8} \mathrm{mim}\right]\left[\mathrm{BF}_{4}\right]$ & 293.15-393.15 & 100 & 0.31 & 0.30 & Gardas et al. (2007b) \\
\hline \multirow[t]{2}{*}[\mathrm{C}_{4}\mathrm{mim}]{$\left[\mathrm{PF}_{6}\right]$} & 293.15-353.15 & 200 & 0.09 & - & Tomida et al. (2006) \\
\hline & 298.15-398.15 & 400 & 0.28 & - & Tekin et al. (2007) \\
\hline \multirow[t]{2}{*}[\mathrm{C}_{6}\operatorname{mim}]{$\left[\mathrm{PF}_{6}\right]$} & 293.15-393.15 & 100 & 0.12 & 0.11 & Gardas et al. (2007b) \\
\hline & $293.15-353.15$ & 200 & 0.10 & - & Tomida et al. (2007a) \\
\hline \multirow[t]{2}{*}[\mathrm{C}_{8}\mathrm{mim}]{$\left[\mathrm{PF}_{6}\right]$} & 293.15-393.15 & 100 & 0.19 & 0.18 & Gardas et al. (2007b) \\
\hline & $293.15-353.15$ & 200 & 0.13 & - & Tomida et al. (2007a) \\
\hline
\end{tabular}

Table 3

Parameters for imidazolium cation head $\left(\mathrm{imi}^{+}\right), \mathrm{Tf}_{2} \mathrm{~N}^{-}, \mathrm{BF}_{4}^{-}$, and $\mathrm{PF}_{6}^{-}$.

\begin{tabular}{|c|c|c|c|c|}
\hline & imi $^{+}$ & $\mathrm{Tf}_{2} \mathrm{~N}^{-}$ & $\mathrm{BF}_{4}^{-}$ & $\mathrm{PF}_{6}^{-}$ \\
\hline$v^{o o}\left(\mathrm{~cm}^{3} / \mathrm{mol}\right)$ & 22.1794 & 78.7377 & 22.7970 & 34.9781 \\
\hline$\lambda$ & 2.3089 & 1.6373 & 1.1014 & 1.1071 \\
\hline$n_{B}$ & 1.2922 & 0 & 0 & 0 \\
\hline$c_{1}(\mathrm{~K})$ & 1007.7533 & 1048.7711 & 352.2533 & -344.5960 \\
\hline$c_{2}$ & -8.595206 & -1.882762 & -0.768297 & 4.477235 \\
\hline$c_{3}\left(\mathrm{~K}^{-1}\right)$ & 0.0260940286 & - & - & - \\
\hline$\varepsilon(\mathrm{K})$ & 1633.7442 & 1788.8889 & 1208.1711 & 8873.4790 \\
\hline $10^{4} \kappa$ & 2.060446 & 2.423795 & 5.203447 & 52.882628 \\
\hline
\end{tabular}

have been extensively investigated. For some of those ILs, several groups of experimental data are available from different research groups. In parameter fitting, we choose the experimental data from the research group of Ferrira (Gardas et al., 2007a,b) because of their extensive experimental work on the ILs of interest and the wide temperature range of the data. For $\mathrm{BF}_{4}$ and $\mathrm{PF}_{6}$ series of ILs, the experimental data from Yokoyama group (Tomida et al., 2006, 2007a) are included because of the wide pressure range of the data. In addition, the liquid density data for $\left[\mathrm{C}_{4} \mathrm{mim}\right]\left[\mathrm{BF}_{4}\right]$ and $\left[\mathrm{C}_{4} \mathrm{mim}\right]\left[\mathrm{PF}_{6}\right]$ from Tekin et al. (2007) are also included because of the disagreement between the experimental $\left[\mathrm{C}_{4} \mathrm{mim}\right]\left[\mathrm{BF}_{4}\right]$ data of Gardas et al. (2007b) and those of Tomida et al. (2006), and the unavailability of experimental $\left[\mathrm{C}_{4} \mathrm{mim}\right]\left[\mathrm{PF}_{6}\right]$ data of Ferrira and Yokoyama at temperatures higher than $353.15 \mathrm{~K}$.

The data from Gardas et al. (2007a,b) at temperatures of 293.15, $313.15,333.15,353.15$, and $393.15 \mathrm{~K}$ and all the data from Tomida et al. (2006, 2007a) and Tekin et al. (2007) are used to fit one set of parameters for imidazolium cation head (imi $\left.{ }^{+}\right), \mathrm{Tf}_{2} \mathrm{~N}^{-}, \mathrm{BF}_{4}^{-}$, and $\mathrm{PF}_{6}^{-}$. The experimental data used for parameter fitting are summarized in Table 2. The fit results for the parameters are listed in Table 3 where $c_{1}, c_{2}$, and $c_{3}$ are the coefficients in Eq. (7). We find that Eq. (7) with the obtained coefficients yields segment energy that is reasonable at least from room temperature up to $450 \mathrm{~K}$. Of course, beyond this temperature range, one should use Eq. (7) with care. The average relative deviation $\left(A R D(\%)=\sum_{i=1}^{N}\left(\left|\rho_{\exp }-\rho_{\text {cal }}\right| / \rho_{\exp }\right) 100 / N\right.$ where $N$ is the number of data points) is $0.21 \%$. The extent of deviation at different temperatures and pressures is shown in Fig. 3. As shown in Fig. 3, the relative deviation is less than $0.6 \%$ for most of the data points. The largest relative deviation is $1.08 \%$ for the data point of $\left[\mathrm{C}_{4} \mathrm{mim}\right]\left[\mathrm{PF}_{6}\right]$ from Tekin et al. (2007) at $398.15 \mathrm{~K}$ and 7.3 bar.

The $A R D$ for each IL is summarized in Table 2 where $A R D_{1}$ represents the deviation based on the data points used in parameter fitting. As shown in Table 2 , the $A R D_{1}$ is less than $0.3 \%$ for most of
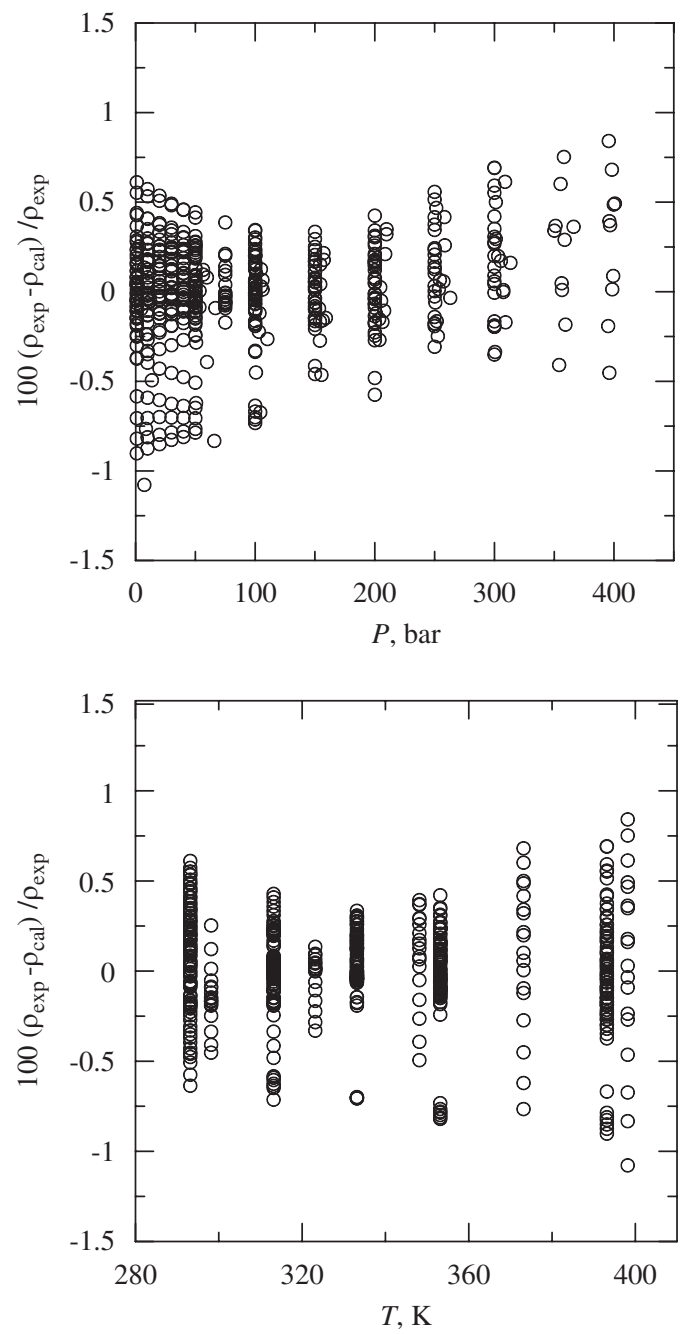

Fig. 3. Percent relative deviation of the calculated liquid densities from the experimental liquid densities used in parameter fitting.

the ILs. For $\left[\mathrm{C}_{4} \mathrm{mim}\right]\left[\mathrm{BF}_{4}\right]$, the $A R D_{1}$ based on the experimental data of Gardas et al. (2007b) is $0.68 \%$ while it is only $0.24 \%$ based on the experimental data of Tomida et al. (2006) and Tekin et al. (2007). Fig. 4 shows the comparison of the calculated and experimental 


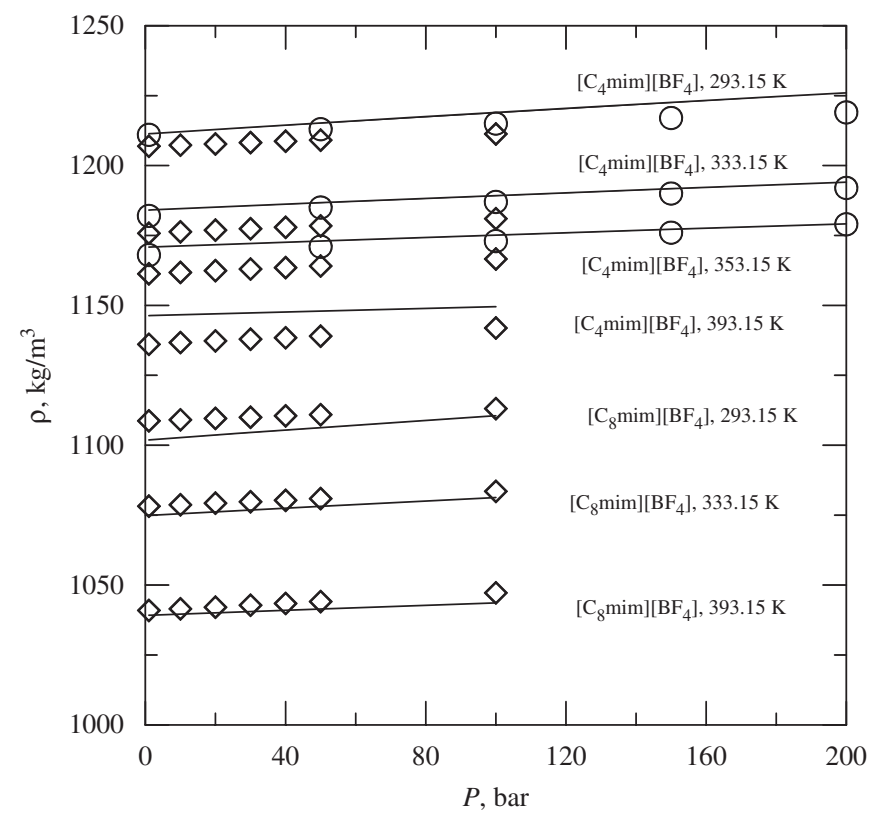

Fig. 4. Liquid densities of $\left[\mathrm{C}_{4} \mathrm{mim}\right]\left[\mathrm{BF}_{4}\right]$ and $\left[\mathrm{C}_{8} \mathrm{mim}\right]\left[\mathrm{BF}_{4}\right]$. $\bigcirc$, experimental data of Tomida et al. (2006); $\diamond$, experimental data of Gardas et al. (2007b);-, calculated results.

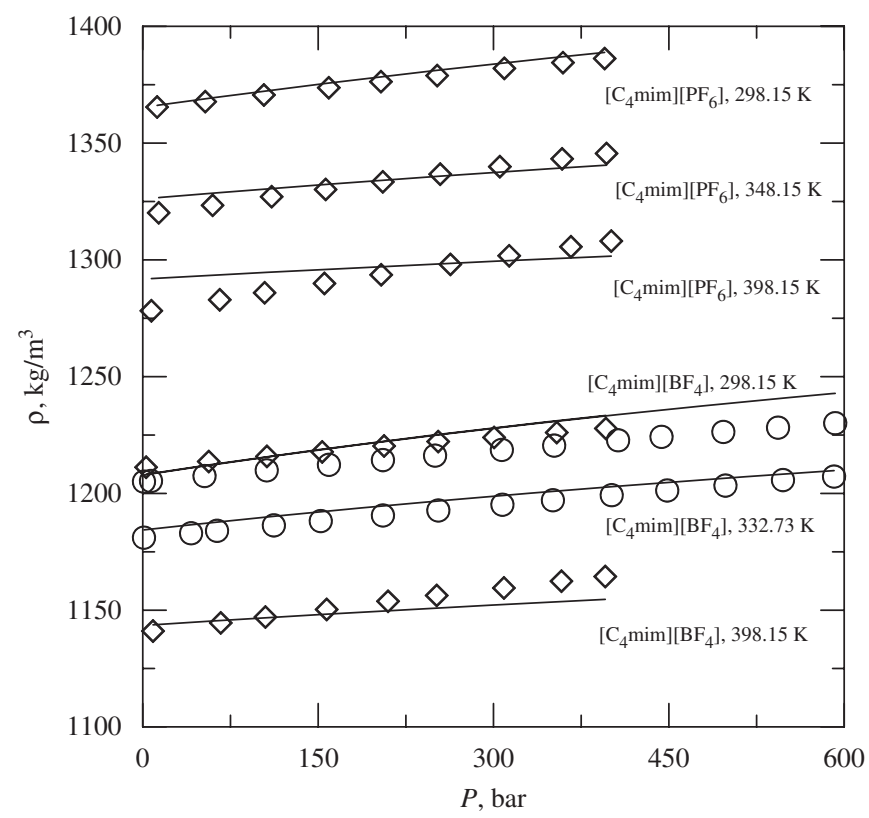

Fig. 5. Liquid densities of $\left[\mathrm{C}_{4} \mathrm{mim}\right]\left[\mathrm{PF}_{6}\right]$ and $\left[\mathrm{C}_{4} \mathrm{mim}\right]\left[\mathrm{BF}_{4}\right] . \diamond$, experimental data of Tekin et al. (2007); $\bigcirc$, experimental data of de Azevedo et al. (2005b);-, calculated results.

liquid densities for $\left[\mathrm{C}_{4} \mathrm{mim}\right]\left[\mathrm{BF}_{4}\right]$ at temperatures of $293.15,333.15$, 353.15 , and $393.15 \mathrm{~K}$ where the experimental data are taken from Gardas et al. (2007b) and Tomida et al. (2006). The experimental data of Gardas et al. (2007b) are lower than those of Tomida et al. (2006) and the calculated results. The calculated results agree well with the experimental data of Tomida et al. (2006).

Fig. 5 shows the comparison of the calculated and experimental liquid densities for $\left[\mathrm{C}_{4} \mathrm{mim}\right]\left[\mathrm{BF}_{4}\right]$ at 298.15 and $398.15 \mathrm{~K}$ where the experimental data are taken from Tekin et al. (2007). At $298.15 \mathrm{~K}$, the model agrees well with the experimental data. At $398.15 \mathrm{~K}$, the

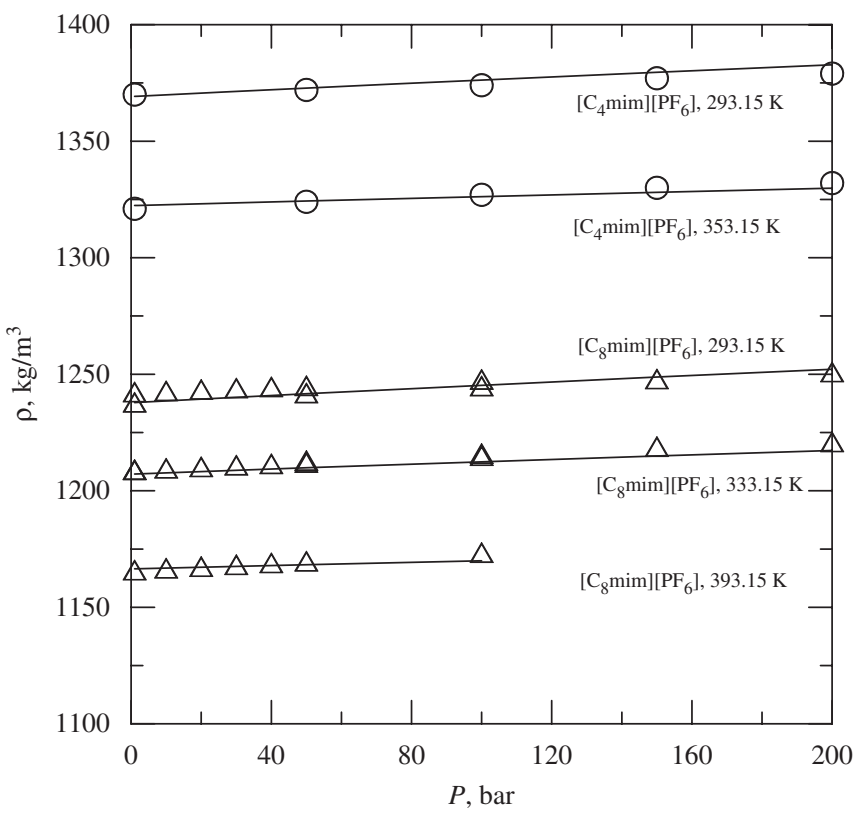

Fig. 6. Liquid densities of $\left[\mathrm{C}_{4} \mathrm{mim}\right]\left[\mathrm{PF}_{6}\right]$ and $\left[\mathrm{C}_{8} \mathrm{mim}\right]\left[\mathrm{PF}_{6}\right] . \bigcirc$, experimental data of Tomida et al. (2006); $\Delta$, experimental data Gardas et al. (2007b); Tomida et al. (2007a);-, calculated results.

model shows some discrepancies at high pressures with the largest deviation of $0.84 \%$.

As shown in Table 2, the $A R D_{1}$ of $\left[C_{8} \mathrm{mim}\right]\left[\mathrm{BF}_{4}\right]$ is not as good as that of others. The comparison of the calculated results with the experimental data (Gardas et al., 2007b) at 293.15, 333.15, and 393.15 K is also depicted in Fig. 4. At high temperatures, the model agrees well with the experimental data, while at low temperatures, the calculated results are lower than the experimental data with the largest deviation of $0.61 \%$ at $293.15 \mathrm{~K}$ and 1.0 bar.

For the other ILs, the $A R D_{1}$ is always less than $0.3 \%$ suggesting the agreement of the model with the experimental data. Fig. 5 also shows the comparison of the calculated and experimental liquid densities for $\left[\mathrm{C}_{4} \mathrm{mim}\right]\left[\mathrm{PF}_{6}\right]$ at $298.15,348.15$, and $398.15 \mathrm{~K}$ where the experimental data are taken from Tekin et al. (2007). At $298.15 \mathrm{~K}$, the model agrees well with the experimental data. At $348.15 \mathrm{~K}$, the calculated results are slightly higher at low pressures and slightly lower at high pressures than the experimental data. At $398.15 \mathrm{~K}$, the calculated results show obvious discrepancies at low pressures. The deviation at $398.15 \mathrm{~K}$ and $7.3 \mathrm{bar}$ is $1.08 \%$, which is the largest deviation for the whole data points used in parameter fitting.

However, for the same IL, as shown in Fig. 6, the model agrees well with the experimental data of Tomida et al. (2006) at temperatures up to $353.15 \mathrm{~K}$ and 200 bar. This means that the experimental data of Tekin et al. (2007) and Tomida et al. (2006) are inconsistent at least around 348 to $353 \mathrm{~K}$. Unfortunately, there is no other experimental data available at temperatures higher than $353.15 \mathrm{~K}$ and, thus, we are unable to verify the accuracy of the experimental data of Tekin et al. (2007) at high temperatures. Fig. 6 also shows the comparison of the calculated and experimental liquid densities for $\left[\mathrm{C}_{8} \mathrm{mim}\right]\left[\mathrm{PF}_{6}\right]$ at $293.15,333.15$, and $393.15 \mathrm{~K}$. The experimental data are from two different research groups (Gardas et al., 2007b; Tomida et al., 2007a) and they agree with the calculated results.

Fig. 7 shows the comparison of the calculated and experimental liquid densities for some $\mathrm{Tf}_{2} \mathrm{~N}$ series ILs. The model agrees well with the experimental data throughout the whole range of temperature and pressure. 


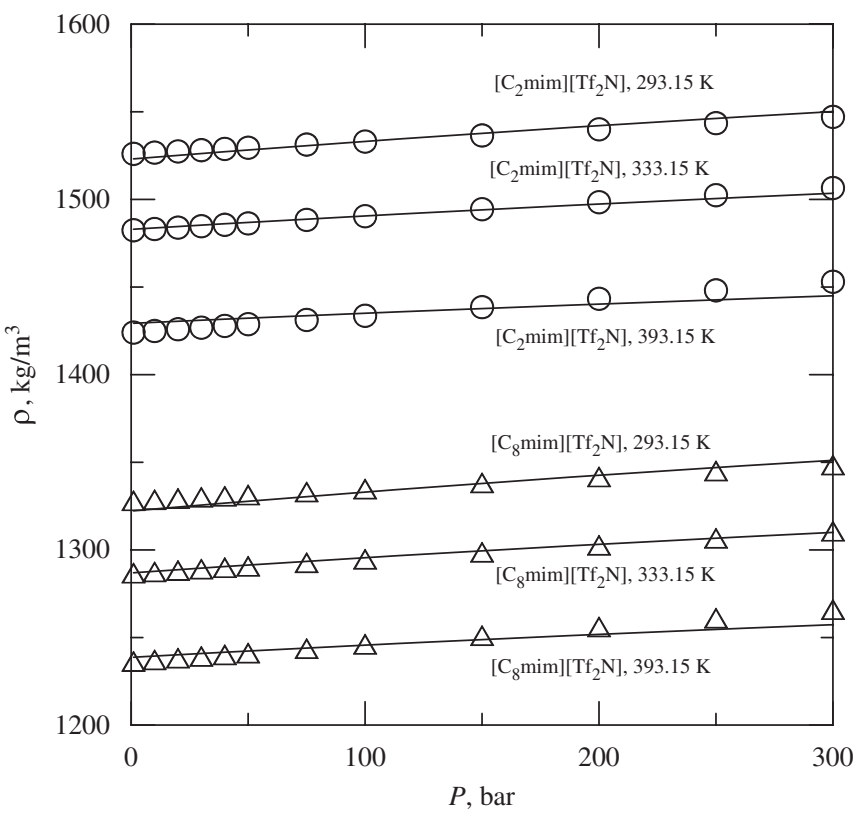

Fig. 7. Liquid densities of $\left[C_{2} \operatorname{mim}\right]\left[\mathrm{Tf}_{2} \mathrm{~N}\right]$ and $\left[\mathrm{C}_{8} \operatorname{mim}\right]\left[\mathrm{Tf}_{2} \mathrm{~N}\right]$. Symbols: experimental data Gardas et al. (2007a);-, calculated results.

\section{Model prediction}

As mentioned earlier, the liquid densities for the ILs studied have been determined extensively. Gardas et al. (2007a,b) measured the liquid densities of imidazolium-based ILs extensively at temperatures from 293.15 to $393.15 \mathrm{~K}$, but only data points at $293.15,313.15$, $333.15,353.15$, and $393.15 \mathrm{~K}$ are used in parameter fitting. The model with the parameters obtained is then initially used to calculate the liquid densities at other temperatures to investigate its interpolation capability. The calculated results are compared with the experimental data of Gardas et al. (2007a,b) at all temperatures. The average relative deviation of this comparison is given in Table 2 as $A R D_{2}$. $A R D_{2} \mathrm{~s}$ have similar values to $A R D_{1} \mathrm{~s}$ for all the investigated ILs, which means that the model is reliable to represent the densities of these ILs at temperatures from 293.15 to $393.15 \mathrm{~K}$.

For the IL series investigated in this work, the experimental liquid densities at higher pressures have been measured by other research groups. For $\left[C_{n} \operatorname{mim}\right]\left[\mathrm{Tf}_{2} \mathrm{~N}\right]$ series ILs, Esperanca et al. (2006) measured the liquid densities of $\left[\mathrm{C}_{3} \operatorname{mim}\right]\left[\mathrm{Tf}_{2} \mathrm{~N}\right]$ and $\left[\mathrm{C}_{5} \operatorname{mim}\right]\left[\mathrm{Tf}_{2} \mathrm{~N}\right]$ at temperatures from 298.15 to $333.15 \mathrm{~K}$ and pressures up to 600 bar. Esperanca et al. (2008) also reported the experimental liquid densities of $\left[\mathrm{C}_{6} \mathrm{mim}\right]\left[\mathrm{Tf}_{2} \mathrm{~N}\right]$ at temperatures from 293.15 to $338.15 \mathrm{~K}$ and pressures up to 650 bar. de Azevedo et al. (2005a) measured the liquid densities of $\left[\mathrm{C}_{4} \mathrm{mim}\right]\left[\mathrm{Tf}_{2} \mathrm{~N}\right]$ at temperatures of 298.15 to $328.20 \mathrm{~K}$ and pressures up to $600 \mathrm{bar}$ and of $\left[\mathrm{C}_{6} \mathrm{mim}\right]\left[\mathrm{Tf}_{2} \mathrm{~N}\right]$ at temperatures of 298.15 to $333.15 \mathrm{~K}$ and pressures up to $600 \mathrm{bar}$. For all of these experimental works, the temperature range was narrow, but th e maximum pressure was high (up to 650 bar).

The model is used to predict the liquid densities of these ILs and compared with the experimental data. The $A R D$ based on the data of Esperanca et al. (2006) is $0.17 \%$ and $0.16 \%$ for $\left[C_{3} \operatorname{mim}\right]\left[\mathrm{Tf}_{2} \mathrm{~N}\right]$ and $\left[\mathrm{C}_{5} \mathrm{mim}\right]\left[\mathrm{Tf}_{2} \mathrm{~N}\right]$, respectively. Fig. 8 shows the experimental and predicted liquid densities for these two ILs at temperatures of 298.15 and $333.15 \mathrm{~K}$ and pressures up to 600 bar. The comparison shows noticeable discrepancies at high pressures. For these two ILs, the largest deviation is $0.57 \%$ for the data point of $\left[\mathrm{C}_{3} \mathrm{mim}\right]\left[\mathrm{Tf}_{2} \mathrm{~N}\right]$ from Esperanca et al. (2006) at $333.15 \mathrm{~K}$ and 600 bar. The low ARD and the results shown in Fig. 8 both demonstrate that the model is reliable

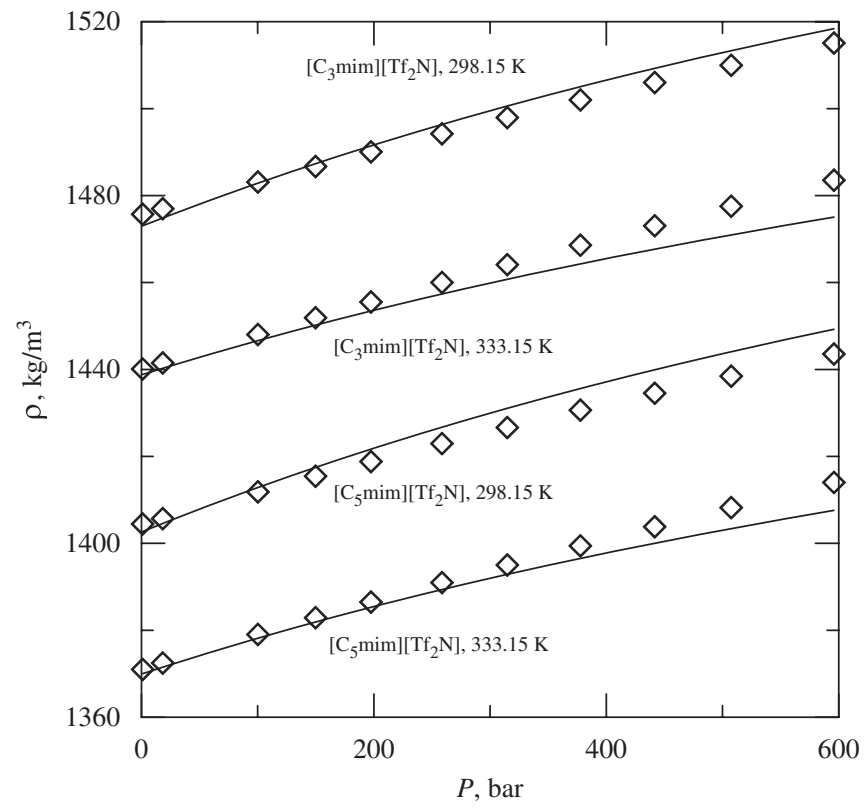

Fig. 8. Liquid densities of $\left[C_{3} \operatorname{mim}\right]\left[\mathrm{Tf}_{2} \mathrm{~N}\right]$ and $\left[C_{5} \operatorname{mim}\right]\left[\mathrm{Tf}_{2} \mathrm{~N}\right] . \diamond$ : experimental data Esperanca et al. (2006);-, predicted results.

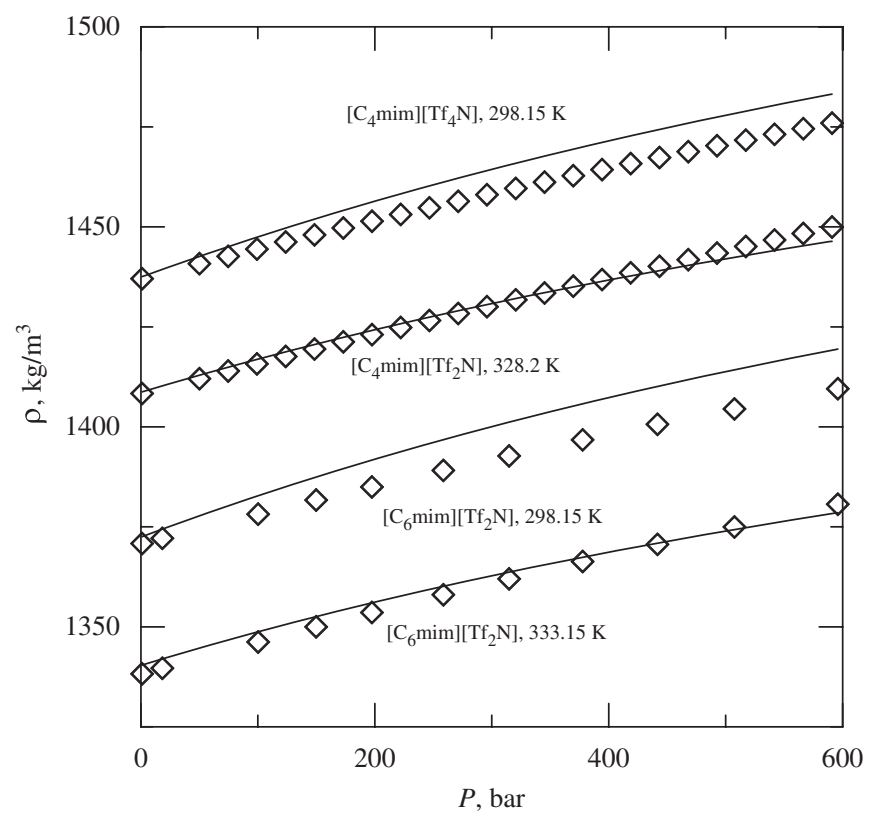

Fig. 9. Liquid densities of $\left[C_{4} \operatorname{mim}\right]\left[\mathrm{Tf}_{2} \mathrm{~N}\right]$ and $\left[\mathrm{C}_{6} \operatorname{mim}\right]\left[\mathrm{Tf}_{2} \mathrm{~N}\right] . \diamond$ : experimental data de Azevedo et al. (2005a);-, predicted results.

to predict the liquid densities for these two ILs at pressures up to 600 bar.

Fig. 9 illustrates the comparison of the predicted results with the experimental data of de Azevedo et al. (2005a) for $\left[\mathrm{C}_{4} \mathrm{mim}\right]\left[\mathrm{Tf}_{2} \mathrm{~N}\right]$ and $\left[\mathrm{C}_{6} \mathrm{mim}\right]\left[\mathrm{Tf}_{2} \mathrm{~N}\right]$ at several temperatures and pressures up to $600 \mathrm{bar}$. The corresponding $A R D \mathrm{~s}$ for $\left[\mathrm{C}_{4} \mathrm{mim}\right]\left[\mathrm{Tf}_{2} \mathrm{~N}\right]$ and $\left[\mathrm{C}_{6} \mathrm{mim}\right]\left[\mathrm{Tf}_{2} \mathrm{~N}\right]$ are $0.19 \%$ and $0.30 \%$, respectively. The result for $\left[\mathrm{C}_{6} \mathrm{mim}\right]\left[\mathrm{Tf}_{2} \mathrm{~N}\right]$ at $298.15 \mathrm{~K}$ and 600 bar shows the largest deviation with a value of $0.70 \%$. The comparison of the predicted results with the experimental data of Esperanca et al. (2008) for [ $\left.\mathrm{C}_{6} \mathrm{mim}\right]\left[\mathrm{Tf}_{2} \mathrm{~N}\right]$ up to $650 \mathrm{bar}$ is also performed. The $A R D$ is $0.23 \%$ with the maximum deviation of $0.73 \%$ at $293.15 \mathrm{~K}$ and 650 bar. Therefore, throughout the whole 
Table 4

ARDs of the predicted liquid densities of ILs.

\begin{tabular}{lllll}
\hline Ionic liquid & $T, \mathrm{~K}$ & $P_{\max }$, bar & $A R D(\%)$ & Ref. \\
\hline$\left[\mathrm{C}_{2} \mathrm{mim}\right]\left[\mathrm{Tf}_{2} \mathrm{~N}\right]$ & $293-415$ & 400 & 0.24 & Jacquemin et al. (2007) \\
{$\left[\mathrm{C}_{3} \mathrm{mim}\right]\left[\mathrm{Tf}_{2} \mathrm{~N}\right]$} & $298.15-333.15$ & 600 & 0.17 & Esperanca et al. (2006) \\
{$\left[\mathrm{C}_{4} \mathrm{mim}\right]\left[\mathrm{Tf}_{2} \mathrm{~N}\right]$} & $293-415$ & 400 & 0.31 & Jacquemin et al. (2007) \\
& $298.15-328.20$ & 591 & 0.19 & de Azevedo et al. (2005a) \\
{$\left[\mathrm{C}_{5} \mathrm{mim}\right]\left[\mathrm{Tf}_{2} \mathrm{~N}\right]$} & $298.15-333.15$ & 600 & 0.16 & Esperanca et al. (2006) \\
{$\left[\mathrm{C}_{6} \mathrm{mim}\right]\left[\mathrm{Tf}_{2} \mathrm{~N}\right]$} & $298.15-333.15$ & 600 & 0.30 & de Azevedo et al. (2005a) \\
& $293.15-338.15$ & 650 & 0.23 & Esperanca et al. (2008) \\
& & & & \\
{$\left[\mathrm{C}_{4} \mathrm{mim}\right]\left[\mathrm{BF}_{4}\right]$} & $293-415$ & 400 & 0.88 & Jacquemin et al. (2007) \\
& $298-333$ & 600 & 0.52 & de Azevedo et al. (2005b) \\
{$\left[\mathrm{C}_{4} \mathrm{mim}\right]\left[\mathrm{PF}_{6}\right]$} & $295-335$ & 200 & 0.08 & Tomida et al. (2007b) \\
& $293-415$ & 400 & 0.24 & Jacquemin et al. (2007) \\
{$\left[\mathrm{C}_{6} \mathrm{mim}\right]\left[\mathrm{PF}_{6}\right]$} & $295-335$ & 200 & 0.10 & Tomida et al. (2007b) \\
{$\left[\mathrm{C}_{8} \mathrm{mim}\right]\left[\mathrm{PF}_{6}\right]$} & $295-335$ & 200 & 0.11 & Tomida et al. (2007b)
\end{tabular}

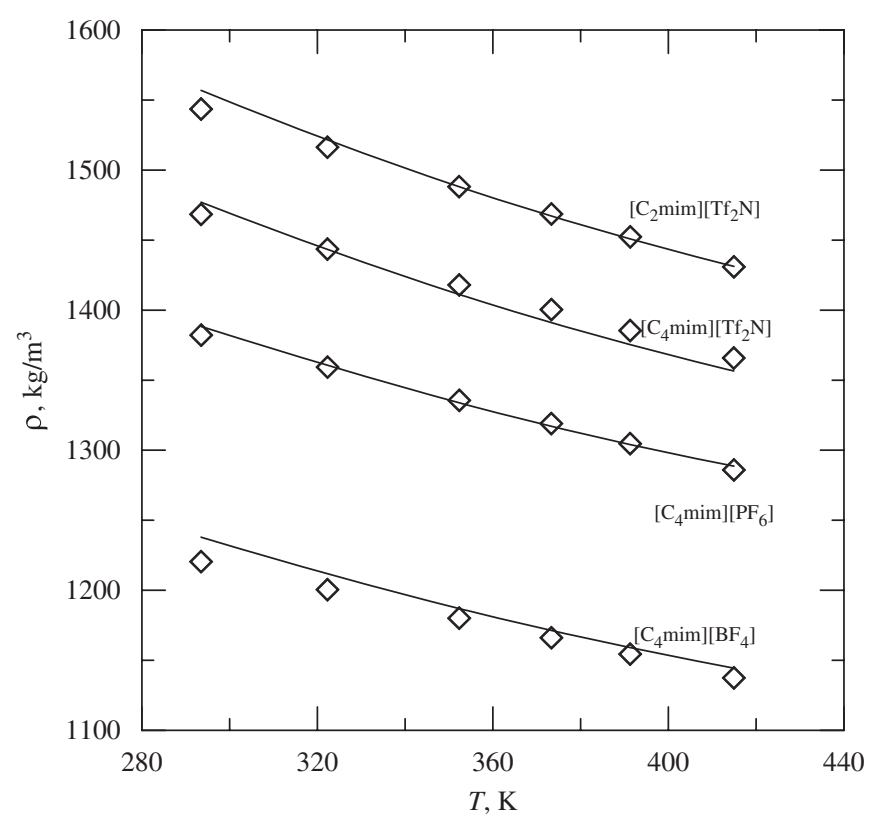

Fig. 10. Liquid densities at 400 bar. $\diamond$ : experimental data of Jacquemin et al. (2007);-, predicted results.

temperature and pressure range, the model agrees well with the experimental data, which again verifies the reliability of the model prediction at pressures up to 650 bar.

Jacquemin et al. (2007) measured the liquid densities of $\left[\mathrm{C}_{2} \mathrm{mim}\right]\left[\mathrm{Tf}_{2} \mathrm{~N}\right]$ and $\left[\mathrm{C}_{4} \mathrm{mim}\right]\left[\mathrm{Tf}_{2} \mathrm{~N}\right]$ at temperatures from 293 to $415 \mathrm{~K}$ and pressures up to $400 \mathrm{bar}$. The model is used to predict the liquid densities and the result is compared with this group of data to verify the model prediction at higher temperatures. Table 4 lists the $A R D$ s of these two ILs, i.e., $0.24 \%$ and $0.31 \%$ for $\left[C_{2} \operatorname{mim}\right]\left[\mathrm{Tf}_{2} \mathrm{~N}\right]$ and $\left[\mathrm{C}_{4} \mathrm{mim}\right]\left[\mathrm{Tf}_{2} \mathrm{~N}\right]$, respectively. Fig. 10 shows the model prediction at 400 bar. The model represents the experimental data well throughout the whole temperature range and captures the effect of temperature and alkyl types on the liquid densities of these ILs.

Liquid densities of $\left[\mathrm{C}_{4} \mathrm{mim}\right]\left[\mathrm{BF}_{4}\right]$ also have been measured in other research groups. de Azevedo et al. (2005b) measured the liquid densities of $\left[\mathrm{C}_{4} \mathrm{mim}\right]\left[\mathrm{BF}_{4}\right]$ at temperatures from 298 to $333 \mathrm{~K}$ and pressures up to 600 bar, and Jacquemin et al. (2007) measured the liquid densities of the same IL at temperatures from 293 to $415 \mathrm{~K}$ and pressures up to 400 bar. The comparison of the predicted results with these two groups of experimental data is performed and the ARDs are also summarized in Table 4. The comparison with the experimental

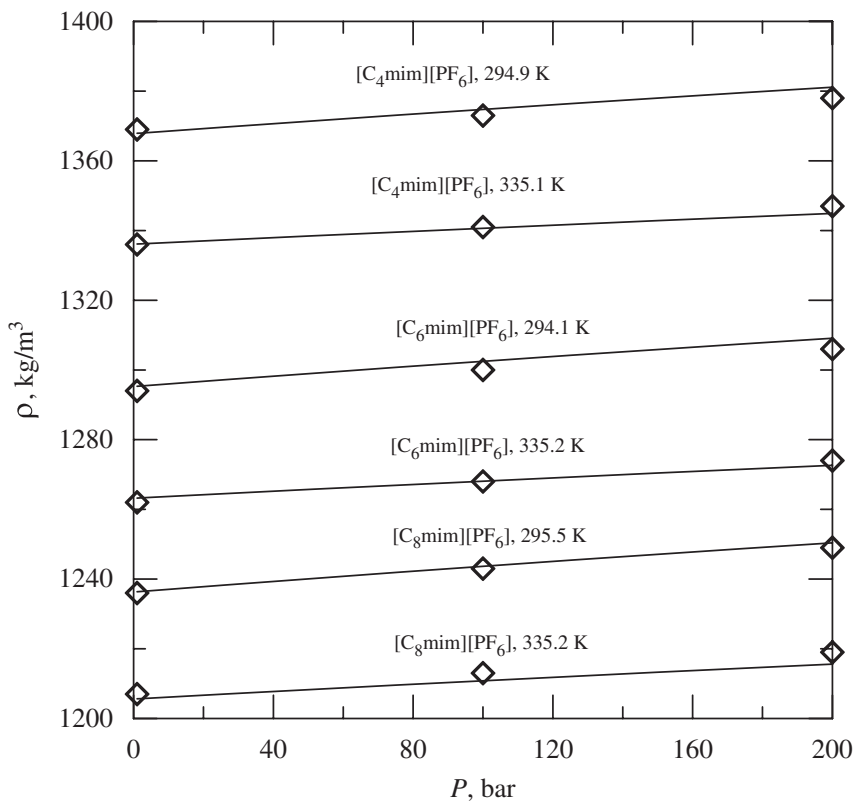

Fig. 11. Liquid densities. $\diamond$ : experimental data of Tomida et al. (2007b);-, predicted results.

data of de Azevedo et al. (2005b) at 298.15 and $332.73 \mathrm{~K}$ and pressures up to 600 bar is depicted in Fig. 5. The model agrees well with the experimental data of de Azevedo et al. (2005b) at $332.73 \mathrm{~K}$, but not at $298.15 \mathrm{~K}$; the experimental data of de Azevedo et al. (2005b) at $298.15 \mathrm{~K}$ are slightly lower than those of Tekin et al. (2007), which agrees well with the model. The comparison of the predicted results with the experimental data of Jacquemin et al. (2007) at 400 bar is also depicted in Fig. 10. Again, the model is consistent with the experimental data at temperatures up to $415 \mathrm{~K}$.

For $\left[C_{n}\right.$ mim $]\left[\mathrm{PF}_{6}\right]$ series ILs, Jacquemin et al. (2007) measured liquid densities of $\left[\mathrm{C}_{4} \mathrm{mim}\right]\left[\mathrm{PF}_{6}\right]$ at temperatures up to $415 \mathrm{~K}$. The $A R D$ of the predicted liquid densities of this IL is summarized in Table 4. Fig. 10 also shows the comparison of the predicted results with the experimental data of Jacquemin et al. (2007) for $\left[\mathrm{C}_{4} \mathrm{mim}\right]\left[\mathrm{PF}_{6}\right]$ at 400 bar with good agreement. Along with the results for $\left[\mathrm{C}_{4} \mathrm{mim}\right]\left[\mathrm{Tf}_{2} \mathrm{~N}\right]$ and $\left[\mathrm{C}_{4} \mathrm{mim}\right]\left[\mathrm{BF}_{4}\right]$, the effect of anion on liquid densities can be observed in that figure. Tomida et al. (2007b) measured the liquid densities of $\left[\mathrm{C}_{4} \mathrm{mim}\right]\left[\mathrm{PF}_{6}\right],\left[\mathrm{C}_{6} \mathrm{mim}\right]\left[\mathrm{PF}_{6}\right]$, and $\left[\mathrm{C}_{8} \mathrm{mim}\right]\left[\mathrm{PF}_{6}\right]$ at temperatures from 295 to $335 \mathrm{~K}$ and pressures up to 200 bar. The comparisons with the predicted results at 295 and $335 \mathrm{~K}$ are shown in Fig. 11 with very good agreement. The ARD s for these three ILs are $0.08,0.10$ and $0.11 \%$, respectively.

\section{Conclusion}

Heterosegmented statistical associating fluid theory is used to represent the density of ionic liquid. Ionic liquid molecule is divided into several groups representing the alkyls, cation head, and anion. The cation of ionic liquid is modeled as a chain molecule that consists of one spherical segment representing the cation head and groups of segments of different types representing different substituents (alkyls). The anion of ionic liquid is modeled as a spherical segment of different type. To account for the electrostatic/polar interaction between the cation and anion, the spherical segments representing cation head and anion each have one association site, which can only cross associate to each other. Each group has five parameters, i.e. segment number $m$, segment volume $v^{o o}$, segment energy $u / k$, the reduced range of the potential well $\lambda$, and group bond number $n_{B}$. In addition to these five parameters, the groups representing 
cation head and anion also have two association parameters, i.e., the well depth of the association site-site potential $\varepsilon$ and the parameter related to the volume available for bonding $\kappa$.

The parameters of alkyls are obtained from those of the corresponding $n$-alkanes by implementing a method used in backbonebranch groups approximation. The parameters of alkyls are found to be well behaved and well represented by simple equations, which provide a basis for estimating parameters for longer alkyls. The parameters of the groups representing cation head and anion, including the two association parameters, are fitted to a group of experimental IL data. The segment energy parameters for the cation head and anion are allowed to vary with temperatures.

The performance of the model is examined by describing the densities of three important series of imidazolium-based ILs, i.e., $\left[C_{n} \operatorname{mim}\right]\left[\mathrm{Tf}_{2} \mathrm{~N}\right],\left[\mathrm{C}_{\mathrm{n}} \mathrm{mim}\right]\left[\mathrm{BF}_{4}\right]$, and $\left[\mathrm{C}_{\mathrm{n}} \mathrm{mim}\right]\left[\mathrm{PF}_{6}\right]$. From experimental data, the density of these ILs increases with decreasing temperature, decreasing carbon number in alkyls, and increasing pressure, but the effect of pressure is much less than that of temperature. With a set of parameters for alkyls, imidazolium cation head, $\mathrm{Tf}_{2} \mathrm{~N}^{-}, \mathrm{BF}_{4}^{-}$, and $\mathrm{PF}_{6}^{-}$, the model is found to well represent the densities of these ILs from 293.15 to $415 \mathrm{~K}$ and up to 650 bar, and well capture the effects of temperature, pressure, and alkyl types on density.

\section{Acknowledgment}

X. Ji thanks Prof. Marcus Öhman for his valuable suggestions and assistance on this work, and thanks Luleå University of Technology for the financial support.

\section{References}

Adidharma, H., Radosz, M., 1998. Prototype of an engineering equation of state for heterosegmented polymers. Ind. Eng. Chem. Res. 37, 4453-4462.

Andreu, J.S., Vega, L.F., 2007. Capturing the solubility behaviour of $\mathrm{CO}_{2}$ in ionic liquids by a simple model. J. Phys. Chem. C 111, 16028-16034.

Antony, J.H., Mertens, D., Breitenstein, T., Dölle, A., Wasserscheid, P., Carper, W.R., 2004. Molecular structure, reorientational dynamics, and intermolecular interactions in the neat ionic liquid 1-butyl-3-methylimidazolium hexafluorophosphate. Pure Appl. Chem. 76, 255-261.

Breure, B., Bottini, S.B., Witkamp, G.J., Peters, C.J., 2007. Thermodynamic modelling of the phase behaviour of binary system of ionic liquids and carbon dioxide with the group contribution equation of state. J. Phys. Chem. B 111, 14265-14270.

de Azevedo, R.G., Esperanca, J.M.S.S., Szydlowski, J., Visak, Z.P., Pires, P.F., Guedes, H.J.R., Rebelo, L.P.N., 2005a. Thermophysical and thermodynamic properties of ionic liquids over an extended pressure range: [bmim] $\left[\mathrm{NTf}_{2}\right]$ and $[\mathrm{hmim}]\left[\mathrm{NTf}_{2}\right]$. J. Chem. Thermodyn. 37, 888-899.

de Azevedo, R.G., Esperanca, J.M.S.S., Najdanovic-Visak, V., Visak, Z.P., Pires, P.F., Guedes, H.J.R., da Ponte, M.N., Rebelo, L.P.N., 2005b. Thermophysical and thermodynamic properties of 1-butyl-3-methylimidazolium tetrafluoroborate and 1-butyl-3-methylimidazolium hexafluorophosphate over an extended pressure range. J. Chem. Eng. Data 50, 997-1008.

Esperanca, J.M.S.S., Visak, Z.P., Plechkova, N.V., Seddon, K.R., Guedes, H.J.R., Rebelo, L.P.N., 2006. Density, speed of sound, and derived thermodynamic properties of ionic liquids over an extended pressure range: 4. $\left[\mathrm{C}_{3} \mathrm{mim}\right]\left[\mathrm{NTf}_{2}\right]$ and $\left[\mathrm{C}_{5} \mathrm{mim}\right]\left[\mathrm{NTf}_{2}\right]$. J. Chem. Eng. Data 51, 2009-2015.

Esperanca, J.M.S.S., Guedes, H.J.R., Lopes, J.N.C., Rebelo, L.P.N., 2008. Pressure-densitytemperature $(\mathrm{p}-\rho-\mathrm{T})$ surface of $\left[\mathrm{C}_{6}\right.$ mim] [NTf2]. J. Chem. Eng. Data 53, 867-870.
Gardas, R.L., Freire, M.G., Carvalho, P.J., Marrucho, I.M., Fonseca, I.M.A., Ferreira, A.G.M., Coutinho, J.A.P., 2007a. P $\rho$ T measurements of imidazolium-based ionic liquids. J. Chem. Eng. Data 52, 1881-1888.

Gardas, R.L., Freire, M.G., Carvalho, P.J., Marrucho, I.M., Fonseca, I.M.A., Ferreira, A.G.M., Coutinho, J.A.P., 2007b. High-pressure densities and derived thermodynamic properties of imidazolium-based ionic liquids. J. Chem. Eng. Data $52,80-88$

Gardas, R.L., Dagade, D.H., Coutinho, J.A.P., Patil, K.J., 2008. Thermodynamic studies of ionic interactions in aqueous solutions of imidazolium-based ionic liquids [Emim] $[\mathrm{Br}]$ and [Bmim][Cl]. J. Phys. Chem. B 112, 3380-3389.

Jacquemin, J., Husson, P., Mayer, V., Cibulka, I., 2007. High-pressure volumetric properties of imidazolium-based ionic liquids: effect of the anion. J. Chem. Eng. Data 52, 2204-2211.

Ji, X., Adidharma, H., 2006. Ion-based SAFT2 to represent aqueous single- and multiple-salt solutions at 298.15 K. Ind. Eng. Chem. Res. 45, 7719-7728.

Ji, X., Adidharma, H., 2007. Ionic-based SAFT2 to represent aqueous single-salt solutions at temperatures and pressures up to $473.15 \mathrm{~K}$ and 1000 bar. Ind. Eng. Chem. Res. 46, 4667-4677.

Ji, X., Adidharma, H., 2008. Ion-based SAFT2 to represent aqueous multiple-salt solutions at ambient and elevated temperatures and pressures. Chem. Eng. Sci. $63,131-140$

Ji, X., Tan, S., Adidharma, H., Radosz, M., 2006. Statistical associating fluid theory coupled with restrictive primitive model extended to bivalent ions. SAFT2: 2. Brine/seawater properties predicted. J. Phys. Chem. B 110, 16700-16706.

Karakatsani, E.K., Economou, I.G., Kroon, M.C., Peters, C.J., Witkamp, G., 2007. tPCSAFT modelling of gas solubility in imidazolium-based ionic liquids. J. Phys. Chem. C 111, 15487-15492.

Kim, Y.S., Jang, J.H., Lim, B.D., Kang, J.W., Lee, C.S., 2007. Solubility of mixed gases containing carbon dioxide in ionic liquids: measurements and predictions. Fluid Phase Equilib. 256, 70-74.

Kroon, M.C., Karakatsani, E.K., Economou, I.G., Witkamp, G., Peters, C.J., 2006 Modeling of the carbon dioxide solubility in imidazolium-based ionic liquids with the tPC-SAFT equation of state. J. Phys. Chem. B 110, 9262-9269.

Meng, Z., Dölle, A., Carper, W.R., 2002. Gas phase model of an ionic liquid: semi-empirical and ab initio bonding and molecular structure. J. Mol. Struct. (Theochem) 585, 119-128.

Shiflett, M.B., Yokozeki, A., 2007. Solubility of $\mathrm{CO}_{2}$ in room temperature ionic liquid [hmim][Tf ${ }_{2}$ N]. J. Phys. Chem. B 111, 2070-2074.

Shin, E., Lee, B., Lim, J.S., 2008. High-pressure solubilities of carbon dioxide in ionic liquids: 1-alkyl-3-methylimidazolium bis (trifluoromethylsulfonyl)imide. J. Supercritical Fluids 45, 282-292.

Simoni, L.D., Lin, Y., Brennecke, J.F., Stadtherr, M.A., 2008. Modeling liquid-liquid equilibrium of ionic liquid systems with NRTL, electrolyte-NRTL, and UNIQUAC Ind. Eng. Chem. Res. 47, 256-272.

Tan S., 2004. SAFT Modeling of complex phase transitions, Doctoral Dissertation, University of Wyoming, 2004.

Tan, S., Ji, X., Adidharma, H., Radosz, M., 2006. Statistical associating fluid theory coupled with restrictive primitive model extended to bivalent ions. SAFT2: 1 . Single salt plus water solutions. J. Phys. Chem. B 110, 16694-16699.

Tekin, A., Safarov, J., Shahverdiyev, A., Hassel, E., 2007. (p, $\rho, \mathrm{T})$ properties of 1butyl-3-methylimidazolium tetrafluoroborate and 1-butyl-3-methylimidazolium hexafluorophosphate at $\mathrm{T}=(298.15$ to 398.15$) \mathrm{K}$ and pressures up to $\mathrm{p}=40 \mathrm{MPa}$. J. Mol. Liquids 136, 177-182.

Tomida, D., Kumagai, A., Qiao, K., Yokoyama, C., 2006. Viscosity of [bmim][PF 6 ] and [bmim] $\left[\mathrm{BF}_{4}\right]$ at high pressure. Int. J. Thermophys. 27, 39-47.

Tomida, D., Kumagai, A., Kenmochi, S., Qiao, K., Yokoyama, K., 2007a. Viscosity of 1-hexyl-3-methylimidazolium hexafluorophosphate and 1-octyl-3methylimidazolium hexafluorophosphate at high pressure. J. Chem. Eng. Data $52,577-579$

Tomida, D., Kumagai, A., Tsukada, T., Qiao, K., Yokoyama, C., 2007b. Thermal conductivities of $[\mathrm{bmim}]\left[\mathrm{PF}_{6}\right],[\mathrm{hmim}]\left[\mathrm{PF}_{6}\right]$ and $[\mathrm{omim}]\left[\mathrm{PF}_{6}\right]$ from 294 to $335 \mathrm{~K}$ at pressures up to $20 \mathrm{MPa}$. Int. J. Thermophys. 28, 1147-1160.

Wang, T., Peng, C., Liu, H., Hu, Y., 2007. Equation of state for the vapour-liquid equilibria of binary system containing imidazolium-based ionic liquids. Ind. Eng. Chem. Res. 46, 4323-4329. 